\title{
Fifth International Scalidophora Workshop
}

Di Domenico, Maikon; Sørensen, Martin V.

Published in:

Zoologischer Anzeiger

DOI:

10.1016/j.jcz.2019.06.002

Publication date:

2019

Document version

Publisher's PDF, also known as Version of record

Document license:

CC BY

Citation for published version (APA):

Di Domenico, M., \& Sørensen, M. V. (2019). Fifth International Scalidophora Workshop. Zoologischer Anzeiger, 282, 1-2. https://doi.org/10.1016/j.jcz.2019.06.002 


\section{Editorial}

\section{Fifth International Scalidophora Workshop}

Scalidophora is an ecdysozoan clade accommodating the phyla Kinorhyncha, Loricifera and Priapulida. Superficially, they might appear very different - the microscopic kinorhynchs with their segmented bodies, the even smaller loriciferans with their trunk covered by a lorica-like body armour, and the unsegmented, vermiform priapulids - but they all share the presence of a head composed of a mouth cone and an eversible introvert with cuticular appendages, the so-called scalids.

The Scalidophora Workshops are organized every third year, and offer a combination of scientific communications and fieldwork. The core participants are Scalidophora taxonomists and morphologists, but the workshops also welcome researchers and students with a general interest in meiofauna ecology and systematics. The present Scalidophora Workshop was the fifth of its kind, and took place on January 28 to February 1, 2019, at the Center for Marine Studies, at the Federal University of Paraná (Centro de Estudos do Mar, CEM/UFPR), in Pontal do Sul, Brazil. Organizers were Maikon Di Domenico (Federal University of Paraná), André R.S. Garraffoni (University of Campinas), and Marcelo V. Fukuda (Zoological Museum of São Paulo), with external support from Martin V. Sørensen (Natural History Museum of Denmark), and invaluable help from local students. Funding for the workshop was generously provided by CAPES (88887.191605/2018-00) and CNPq (401532/ 2018-6).

A total 30 researchers and students from nine different countries and seventeen different universities participated at the workshop (Fig. 1). The scientific program included six plenary lectures and sixteen contributed talks, covering a broad range of aspects, inclusive taxonomy, morphology, ecology and genomics of scalidophorans. The output of the workshop includes sixteen original papers that were communicated during the workshop and published in the present special issue of Zoologischer Anzeiger. Selected talks and interviews with researchers can furthermore be seen at the Scalidophora Workshop YouTube-channel: https:// www.youtube.com/channel/UCPXwfOgIMOVzVHzcHI55xlQ.

On behalf of the organizing committee we would like to thank all workshop participants, contributors to this special issue, student helpers, Professor Paulo C. Lana and the staff of CEM, Federal University of Paraná, and the funding agencies. The VI International Scalidophora Workshop will be arranged by Andreas SchmidtRhaesa, University of Hamburg, Germany, and is scheduled to take place in the summer of 2021.

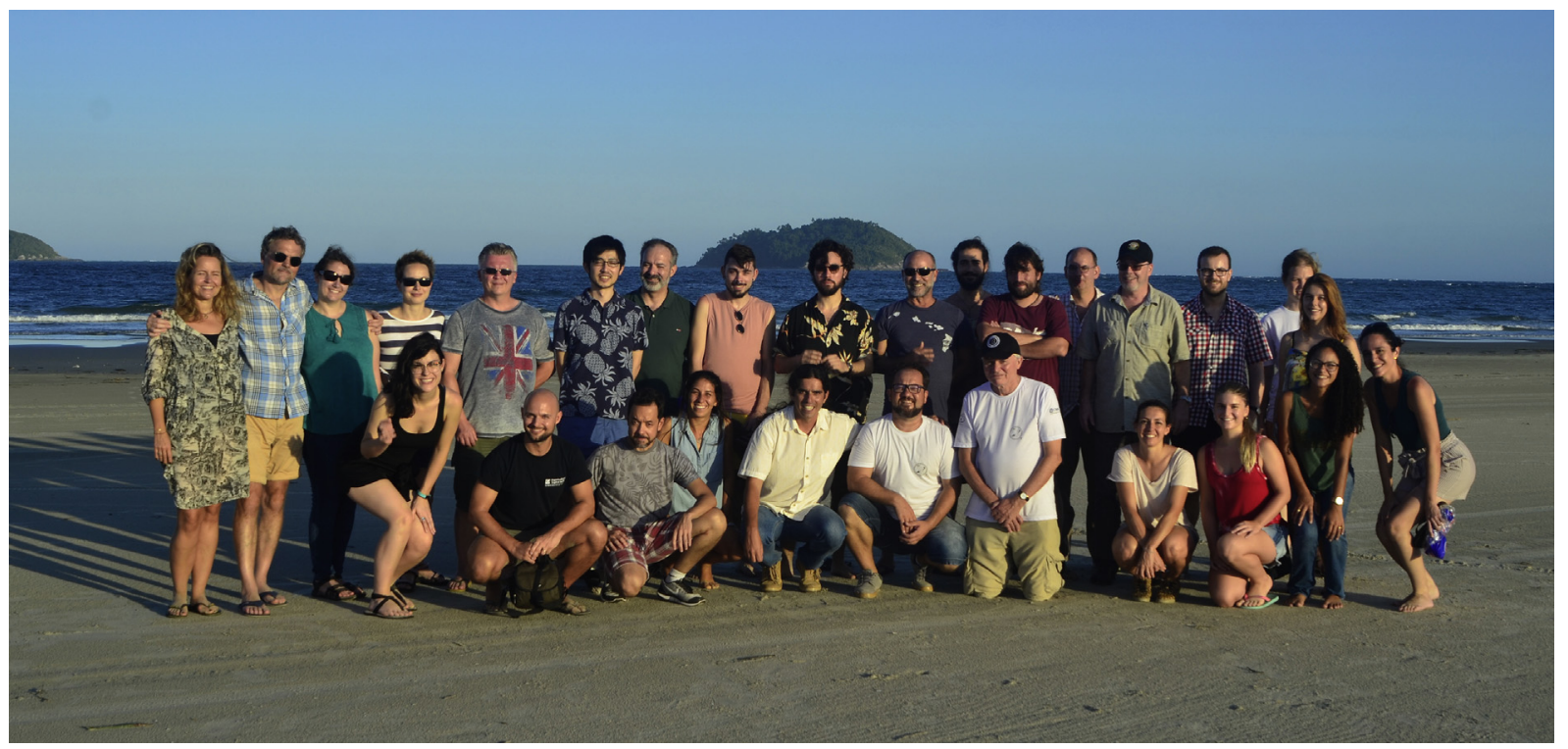

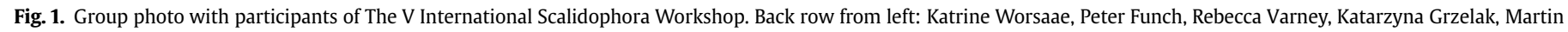

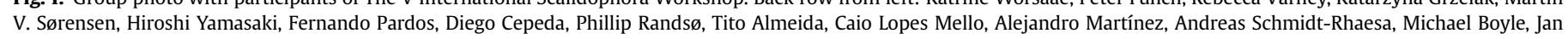

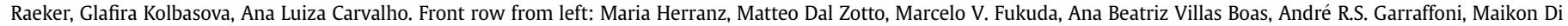
Domenico, Reinhardt M. Kristensen, Nuria Sánchez, Ana Carla Massocatto, Emanuely Ezidio, and Ana Carolina Vilas-Boas. 
Maikon Di Domenico Center for Marine Studies, Federal University of Paraná State, Pontal do Paraná, Brazil

Martin V. Sørensen*

Natural History Museum of Denmark, University of Copenhagen, Universitetsparken 15, 2100 Copenhagen, Denmark
* Corresponding author. E-mail address: mvsorensen@snm.ku.dk (M.V. Sørensen).

Available online 15 June 2019 